\title{
Ultrasensitive and Highly Selective Electrochemical Detection of Dopamine Using Poly(ionic liquids)-Cobalt Polyoxometalate/CNT Composite
}

Neha Thakur, Subhasis Das Adhikary, Mukesh Kumar, Daisy Mehta, Anil K. Padhan, Debaprasad Mandal,*(i) and Tharamani C. Nagaiah*(0)

Department of Chemistry, Indian Institute of Technology Ropar, Rupnagar, Punjab 140001, India

Supporting Information

ABSTRACT: A novel sandwich polyoxometalate (POM) $\mathrm{Na}_{12}\left[\mathrm{WCo}_{3}\left(\mathrm{H}_{2} \mathrm{O}\right)_{2}\left(\mathrm{CoW}_{9} \mathrm{O}_{34}\right)_{2}\right]$ and poly(vinylimidazolium) cation $\left[\mathrm{PVIM}^{+}\right.$] in combination with nitrogen-doped carbon nanotubes (NCNTs) was developed for a highly selective and ultrasensitive detection of dopamine. Conductively efficient heterogenization of $\mathrm{Co}_{5} \mathrm{POM}$ catalyst by PVIM over NCNTs provides the synergy between PVIM-POM catalyst and NCNTs as a conductive support which enhances the electron transport at the electrode/ electrolyte interface and eliminates the interference of ascorbic acid (AA) at physiological $\mathrm{pH}$ (7.4). The novel PVIM-Co 5 POM/NCNT composite demonstrates a superior selectivity and sensitivity with a lowest detection limit of $500 \mathrm{pM}(0.0005 \mu \mathrm{M})$ and a wide linear detection range of $0.0005-600$ $\mu \mathrm{M}$ even in the presence of higher concentration of AA $(500 \mu \mathrm{M})$.

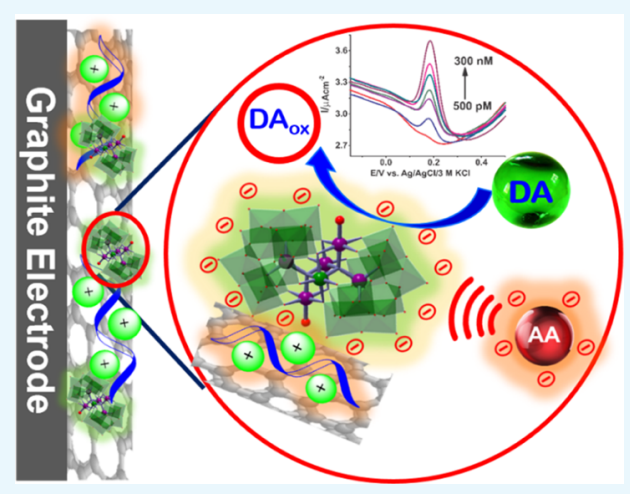

\section{INTRODUCTION}

Dopamine (DA) is an important neurotransmitter in the brain's limbic reward system which plays a significant role in functioning of cardiovascular system, renal and transferring the information to different parts of brain mainly by the rewardmotivated pathway. ${ }^{1,2}$ The abnormal levels of DA are shown to have a significant effect on neurological disorders that are linked to Parkinson's, Schizophrenia, Alzheimer's disease, and human immunodeficiency virus pathogenesis. ${ }^{3}$ Hence, sensitive and selective determination of the DA level is extremely important for the early diagnosis and prevention of these diseases for the well-being of human health. For a healthy individual, DA level lies in the range of $0.01-10 \mu \mathrm{M}^{4}$

Among various techniques used for the detection of DA, electrochemical methods are in vogue because of its quick response, high sensitivity and more importantly, easy electrooxidation of DA makes it more viable. However, the coexistence of uric acid (UA) and a high concentration of ascorbic acid [AA 100-1000 times higher than DA] in the extracellular fluids of the central nervous system can cause great interference because of its oxidation potentials which are close to that of DA on bare electrodes resulting in poor selectivity. Moreover, the electro-oxidation of DA in the presence of AA results in regeneration of DA by reducing back the oxidized DA by $\mathrm{AA}$ and then reoxidizing at the electrode surface making the system unreliable.

Hence, it is of great importance to develop a highly selective and sensitive probe capable enough to completely knock down the interference of AA and UA for an efficient and quick therapeutics. Numerous efforts have been made in eliminating the interference of AA and the selective detection of DA. For example, transition metal oxides, noble metals, ${ }^{6-8} \mathrm{Ag}-\mathrm{Pt} /$ carbon nanofibers, ${ }^{9}$ boron-doped diamond electrode, ${ }^{5}$ peptide nanostructures, ${ }^{10}$ polymer, ${ }^{11}$ and functionalized carbonaceous nanomaterials ${ }^{12}$ have been explored. Nevertheless, extremely low concentration of DA in the presence of high concentration of AA imposes severe limitations for the existing catalyst materials.

Polyoxometalates (POMs) are high-oxidation-state transition metaloxide clusters that have attracted a great attention in numerous applications toward material science, ${ }^{13}$ catalyst in homogeneous and heterogeneous system, ${ }^{14-16}$ energy storage systems, ${ }^{17}$ electrocatalysis, ${ }^{18}$ and medicine. ${ }^{19}$ It is also used in electrochemical sensing because of its multielectron redox properties and high stability without altering the composition; furthermore, its physical properties can be fine-tuned by varying the cations. A few reports of DA-sensing by POM are also reported, ${ }^{20,21}$ but high solubility in water, lack of selectivity, and poor conductivity restrict its use in electrochemical sensing of DA. In the present report, we have explored a novel sandwich POM $\mathrm{Na}_{12}\left[\mathrm{WCo}_{3}\left(\mathrm{H}_{2} \mathrm{O}\right)_{2}\left(\mathrm{CoW}_{9} \mathrm{O}_{34}\right)_{2}\right] \quad\left(\mathrm{Na}_{12} \mathrm{Co}_{5} \mathrm{POM}\right)$, wherein both $\mathrm{Co}$ and $\mathrm{W}$ metals are non-noble, cost-effective, ecofriendly and stable in the $\mathrm{pH}$ range of 4.0-8.0. In general, sandwich POMs are more accessible and are better catalysts than simple keggin POMs. To the best of our knowledge, this sandwich $\mathrm{Co}_{5} \mathrm{POM}$ has never been explored in catalysis or any

Received: December 22, 2017

Accepted: February 23, 2018

Published: March 12, 2018 
other applications. Here, we demonstrate an outstanding performance of $\mathrm{Co}_{5} \mathrm{POM}$ as a sensor for the detection of DA by using a conjugate of POM and poly(vinylimidazolium) cation $\left[\mathrm{PVIM}^{+}\right]$in combination with nitrogen-doped carbon nanotubes (NCNTs). $\mathrm{Co}_{5} \mathrm{POM}$ was supported over NCNTs to enhance the electron transfer between poorly conductive POMs and the external circuit. However, NCNTs ${ }^{12}$ and $\mathrm{POM}^{20,21}$ independently cannot eliminate the interference of $\mathrm{AA}$ and $\mathrm{UA}$ in the determination of DA. [ $\left.\mathrm{PVIM}^{+}\right]$was introduced as a cationic polymer (ionomer) to balance the multinegative charge $(-12)$ of $\mathrm{Co}_{5} \mathrm{POM}$ and strongly hold both NCNT and POM while allowing the uniform distribution over NCNT support. Conductively efficient heterogenization of $\mathrm{Co}_{5} \mathrm{POM}$ catalyst by PVIM over NCNTs provides the synergy between PVIM-POM catalyst and NCNTs as a conductive support at the electrode/electrolyte interface which enhances the sensitivity and selectivity toward the electrochemical detection of DA (Scheme 1) and eliminates the interference of $\mathrm{AA}$ at a physiological $\mathrm{pH}$ (7.4).

Scheme 1. Schematic Representation of PVIM-Co 5 POM/ NCNT Composite Interactions with DA and AA at the Electrode/electrolyte Interface

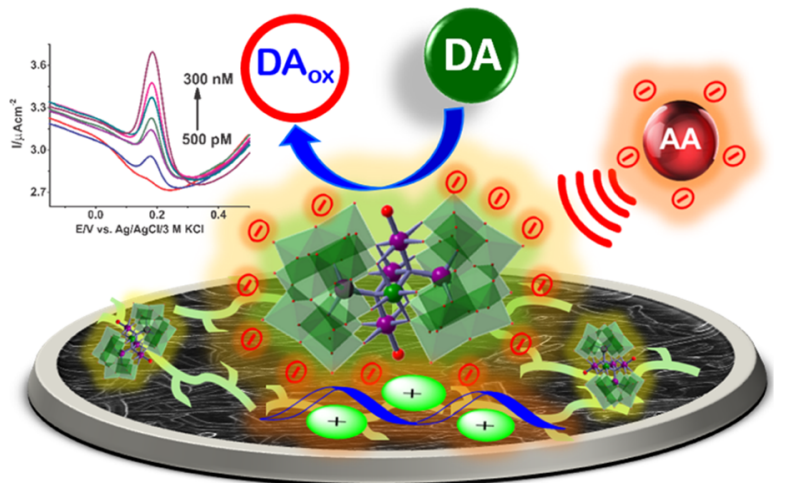

\section{RESULTS AND DISCUSSION}

Physical Characterization. In the present study, we have shown that PVIM- $-\mathrm{Co}_{5} \mathrm{POM}$ conjugate is a stable catalyst to perform sensitive and selective detection of DA. Our approach was to improve the conductivity and simultaneously enhanced electron transfer of novel $\mathrm{Co}_{5} \mathrm{POM}$ molecular catalyst for a selective electrochemical detection of DA using PVIM polymer matrix and NCNTs.

The sandwich $\mathrm{Na}_{12}\left[\mathrm{Co}_{5} \mathrm{POM}\right]$ was synthesized under microwave heating and the green-colored crystals was obtained from recrystallization under slow evaporation of the aqueous mixture (detailed in Experimental Section). The molecular structure was analyzed by single-crystal X-ray diffraction (SC$\mathrm{XRD}$ ) and is depicted in Figure 1 and Table S3 (Supporting Information, CCDC no. 1558372). As revealed by the molecular structure, three Co atoms and one $\mathrm{W}$ atom formed a cubane which is sandwiched between two $\left[\mathrm{CoW}_{9} \mathrm{O}_{34}\right]$ Keggin fragments. The molecular formula of the compound was found to be $\mathrm{Na}_{12}\left[\mathrm{WCo}_{3}\left(\mathrm{H}_{2} \mathrm{O}\right)_{2}\left(\mathrm{CoW}_{9} \mathrm{O}_{34}\right)_{2}\right]$. Tweleve $\mathrm{Na}$ atoms surrounded the $\mathrm{Co}_{5} \mathrm{POM}$ as counter-cation. All the $\mathrm{W}$ atoms present in the structure are octahedrally surrounded by $\mathrm{O}$ atoms. The Col atoms (namely heteroatoms) are tetrahedrally surrounded by $\mathrm{O}$ atoms, whereas the sandwiched $\mathrm{Co}$ atoms namely $\mathrm{Co} 2$ and $\mathrm{Co} 3$ are in octahedral geometry.

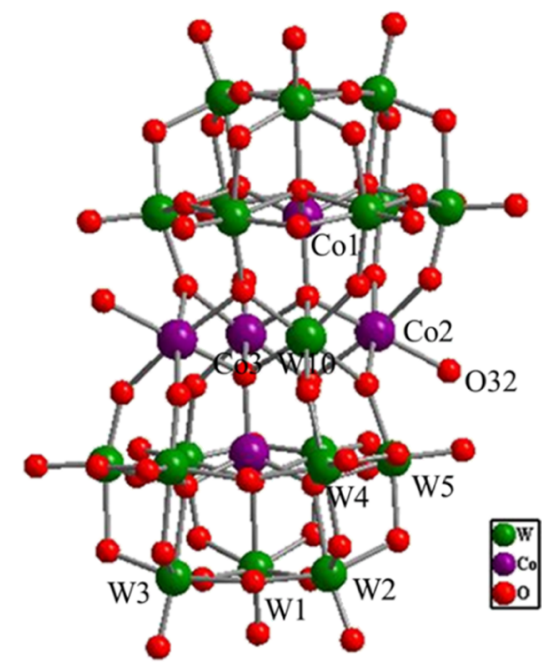

Figure 1. Single-crystal X-ray structure of $\left[\mathrm{WCo}_{3}\left(\mathrm{H}_{2} \mathrm{O}\right)_{2}\right.$ $\left.\left(\mathrm{CoW}_{9} \mathrm{O}_{34}\right)_{2}\right]^{12-}$.

The sixth coordination site of each terminal Co atom Co 2 is occupied by $\mathrm{O}$ atoms of water molecules. The sandwiched Co and $\mathrm{W}$ atoms ( $\mathrm{Co} 2, \mathrm{Co} 3$, and $\mathrm{W} 10)$ are connected to each other by oxo-bridges. Moreover, $\mathrm{Co} 3$ and $\mathrm{W} 10$ atoms are sharing the same sites because of positional disorder. Further, the detailed crystal parameters of $\mathrm{Co}_{5} \mathrm{POM}$ (extracted from the SC-XRD analysis) are given in Table S3 (Supporting Information).

The conjugate of $\mathrm{Co}_{5} \mathrm{POM}$ and PVIM was prepared using slight excess of PVIMBr to replace the $\mathrm{Na}$ ions in $\mathrm{Na}_{12}\left[\mathrm{Co}_{5} \mathrm{POM}\right]$ resulting in a concrete light green solid, where PVIM acts as a binder. The PVIM- $\mathrm{Co}_{5} \mathrm{POM} / \mathrm{NCNTs}$ composite was prepared by homogeneously grinding the mixture of PVIM- $\mathrm{Co}_{5} \mathrm{POM}$ conjugate and NCNTs (70:30 wt $\%)$ for $1 \mathrm{~h}$. The resultant PVIM- $\mathrm{Co}_{5} \mathrm{POM} / \mathrm{NCNT}$ composite was characterized in detail using Fourier transform infrared (FT-IR) spectroscopy, scanning electron microscopy (SEM), and X-ray photo electron spectroscopy (XPS) techniques. Additionally, UV-vis and FT-IR spectroscopic studies were carried out for $\mathrm{Co}_{5} \mathrm{POM}$ and have been provided as Figures S3 and S4 (Supporting Information), respectively. FT-IR analysis shows all the $\mathrm{W}-\mathrm{O}$ characteristic stretching frequencies and $\nu_{\mathrm{C}=\mathrm{N}}\left(1159 \mathrm{~cm}^{-1}\right)$, slightly shifted to 1164 $\mathrm{cm}^{-1}$ in PVIM-Co $\mathrm{POM} / \mathrm{NCNT}$ s composite compared to PVIM- $\mathrm{Co}_{5} \mathrm{POM}$ conjugate (Figure S5, Supporting Information). The SEM images (Figures $2 \mathrm{~b}$ and S6, Supporting Information) display the morphology of $\mathrm{Co}_{5} \mathrm{POM}, \mathrm{PVIM}-$ $\mathrm{Co}_{5} \mathrm{POM}$ conjugate, and PVIM- $\mathrm{Co}_{5} \mathrm{POM} / \mathrm{NCNT}$ composite. It can be seen from the images that $\mathrm{Co}_{5} \mathrm{POM}$ displays no distinguishable structural features and is basically nonconductive resulted in contrast difference because of the electrostatic charge accumulation on the surface (Figure S6). The optical images of $\mathrm{Na}_{12} \mathrm{Co}_{5} \mathrm{POM}$ and PVIM-Co $\mathrm{POM}$ conjugate in Figure S6c (Supporting Information) reveal the dark green crystals, which forms light green concrete solid after the exchange of cation with PVIM, in which PVIM acts as a binder. The same aggregation of the PVIM- $\mathrm{Co}_{5} \mathrm{POM}$ conjugate can be seen in SEM images (Figure S6, Supporting Information). However, after the physical mixing of NCNTs with PVIM$\mathrm{Co}_{5} \mathrm{POM}$ resulted in the formation of fairly homogeneous layer around the NCNTs (Figure 2). 

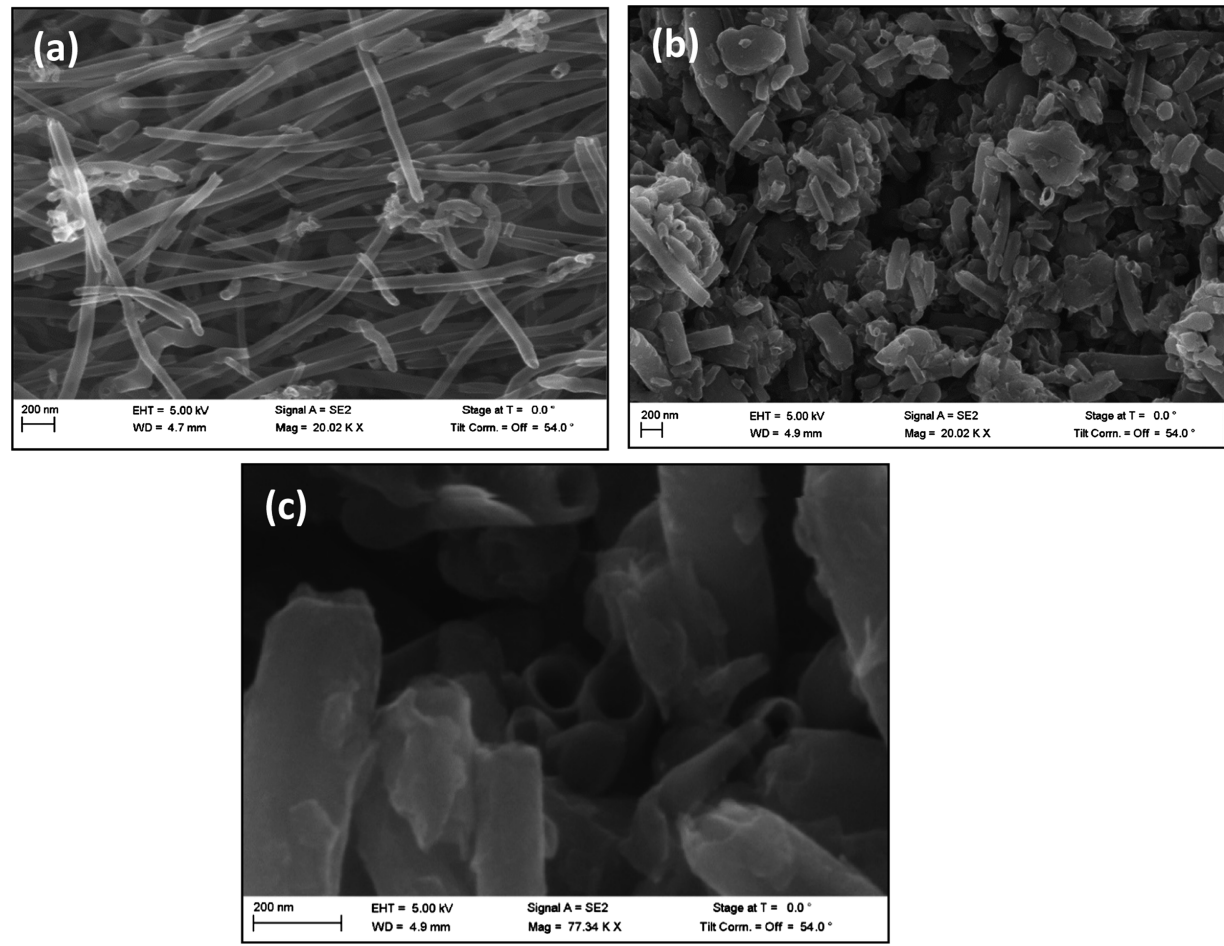

Figure 2. FE-SEM images of (a) NCNTs, (b) and (c) PVIM- $\mathrm{Co}_{5} \mathrm{POM} / \mathrm{NCNT}$ composite at lower and higher magnification, respectively.
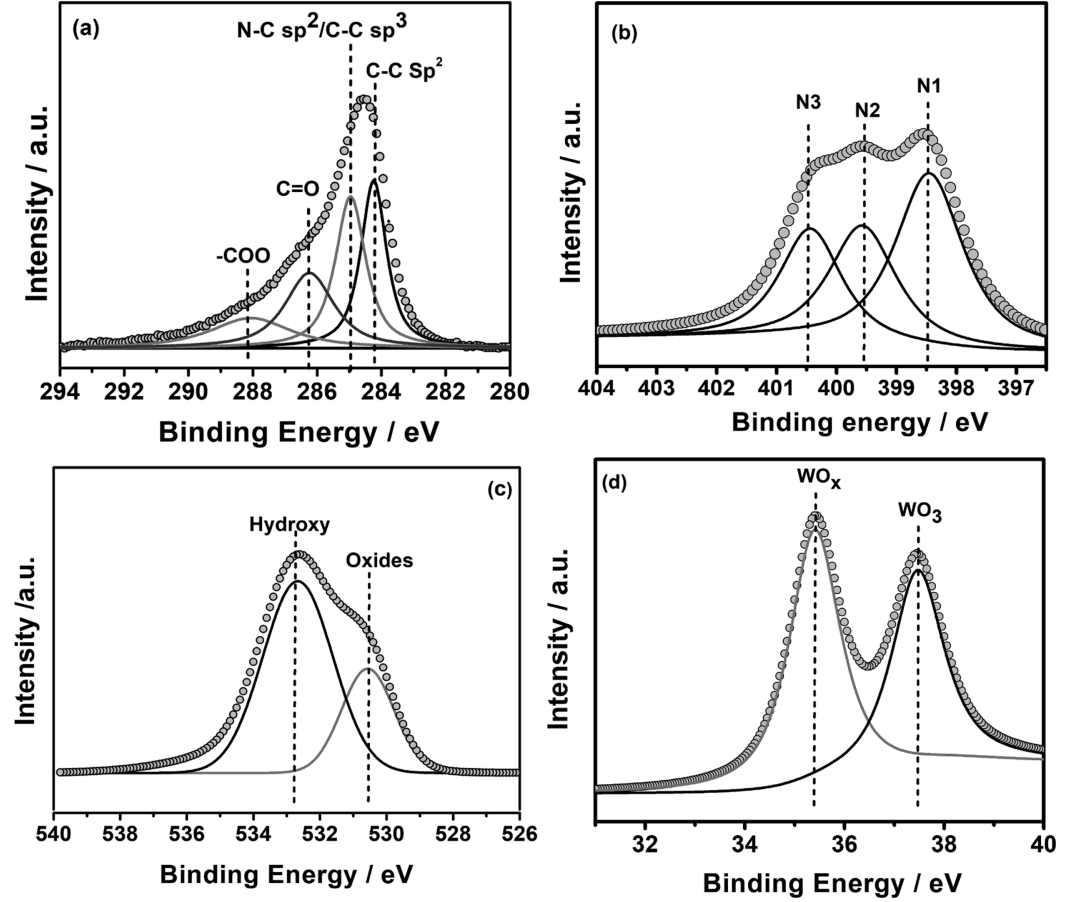

Figure 3. Deconvoluted XP spectra of (a) C 1s, (b) N 1s, (c) O 1s, and (d) W 4f for the PVIM-Co ${ }_{5} \mathrm{POM} / \mathrm{NCNT}$ composite.

The elemental surface composition of PVIM- $\mathrm{Co}_{5} \mathrm{POM} /$ NCNT composite material investigated using XPS. The XPS survey scan revealed the presence of carbon $(\mathrm{C})$, oxygen $(\mathrm{O})$, nitrogen $(\mathrm{N})$, tungsten $(\mathrm{W})$, and cobalt (Co) (Figure S7, Supporting Information). Figure 3a represents C 1s XP spectra of the composite, and the spectra were deconvoluted into four components. The two main peaks at 284.2 and 285.0 were attributed to $\mathrm{sp}^{2}$-hybridized graphite-like carbon $\left(\mathrm{C}-\mathrm{C} \mathrm{sp}^{2}\right)$ and $\mathrm{sp}^{3}$-hybridized diamond-like carbon $\left(\mathrm{C}-\mathrm{C} \mathrm{sp}^{3}\right)$ respec- tively overlapping with $\mathrm{sp}^{2}$ carbon bound to nitrogen $(\mathrm{N}-\mathrm{C}$ $\left.\mathrm{sp}^{2}\right)$ present in the NCNTs as well as in PVIM. The peaks at 286.2 and 288.1 were assigned to carbon-oxygen functional groups (labeled as $\mathrm{C}-\mathrm{O}, \mathrm{C}=\mathrm{O}$ and $-\mathrm{COO}$ ). The N1s XP spectra (Figure $3 \mathrm{~b}$ ) exhibits three main peaks, one at the lowest binding energy $(398.5 \mathrm{eV})$ can be attributed to pyridinic nitrogen (N1), the peak at $399.5 \mathrm{eV}$ originates from pyrrolic nitrogen (N2), and the higher binding energy peak at $400.4 \mathrm{eV}$ assigned to quaternary group (N3) present in NCNTs and in 

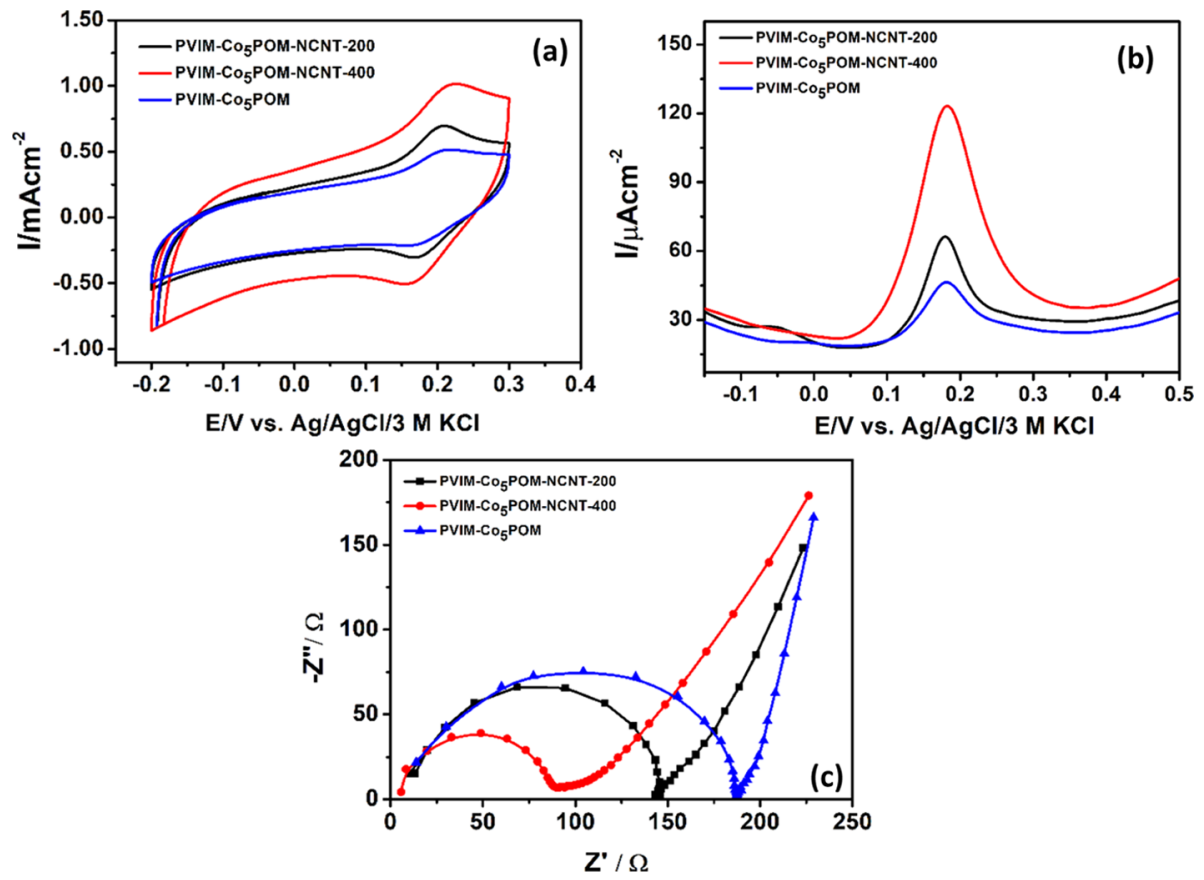

Figure 4. (a) Cyclic voltammograms, (b) corresponding DPV, and (c) EIS of various catalysts on graphite electrode in 0.1 M PBS (pH 7.0) solution containing $500 \mu \mathrm{M} \mathrm{AA}$ and $50 \mu \mathrm{M} \mathrm{DA}$ performed at a scan rate of $75 \mathrm{mV} \mathrm{s}^{-1}$, counter electrode (CE): $\mathrm{Pt}$ wire, reference electrode (RE): $\mathrm{Ag} / \mathrm{AgCl} /$ $3 \mathrm{M} \mathrm{KCl}$.
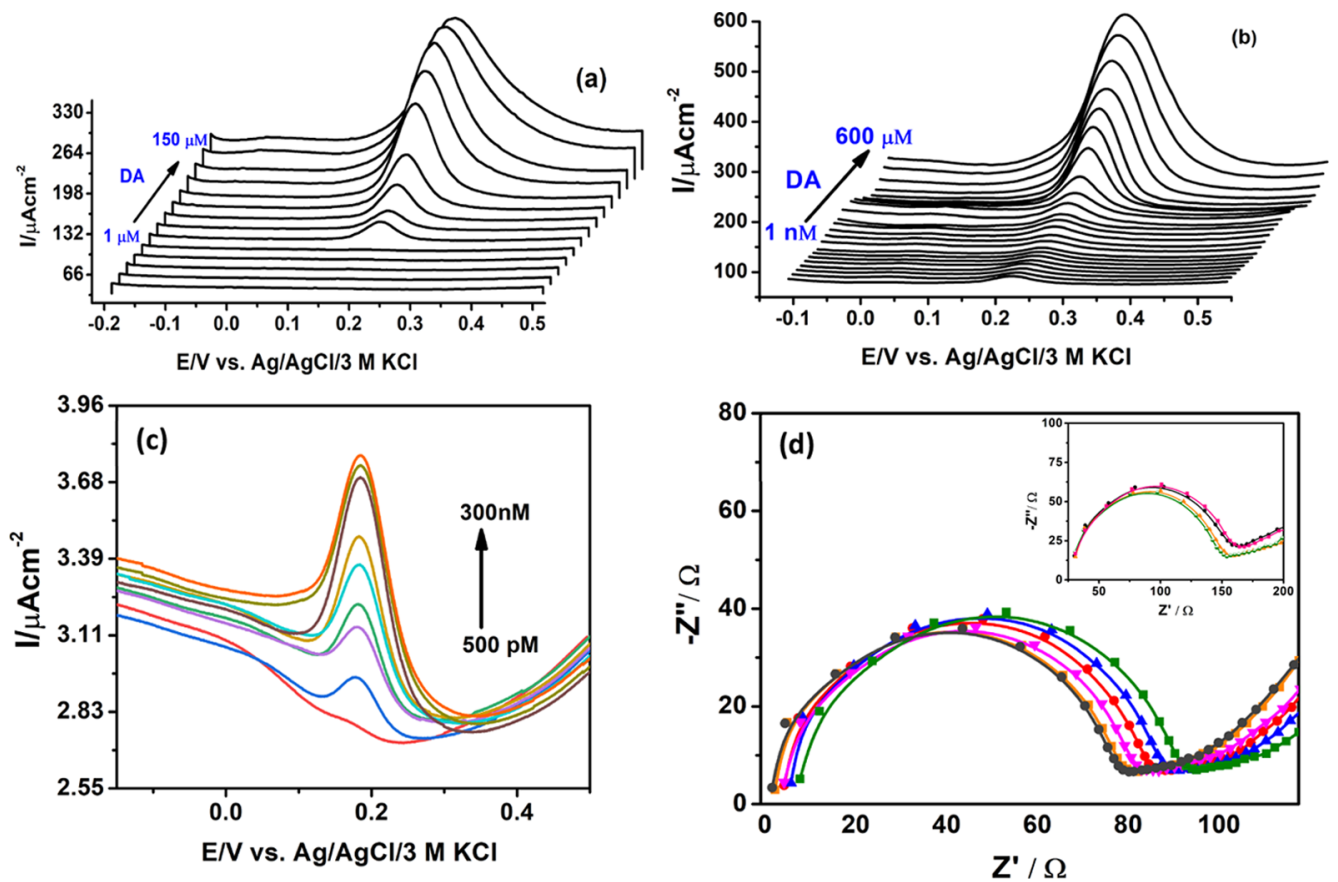

Figure 5. Differential pulse voltammograms of (a) PVIM- $\mathrm{Co}_{5} \mathrm{POM}$; (b,c) PVIM- $\mathrm{Co}_{5} \mathrm{POM} / \mathrm{NCNT}-400$ at a step potential $10 \mathrm{mV}$, pulse amplitude of $2 \mathrm{mV}$, pulse width of $500 \mathrm{~ms}$, and scan rate of $10 \mathrm{mV} \mathrm{s}$; and (d) EIS of PVIM-Co $\mathrm{Co}_{5} \mathrm{POM} / \mathrm{NCNT}-400$ in $0.1 \mathrm{M} \mathrm{PBS}$ (pH 7.0) solution containing $500 \mu \mathrm{M} \mathrm{AA}$ and various concentrations of DA (inset lower concentration of DA); $\mathrm{CE}$ : Pt wire; and $\mathrm{RE}: \mathrm{Ag} / \mathrm{AgCl} / 3 \mathrm{M} \mathrm{KCl}$.

PVIM. The $\mathrm{O} 1 \mathrm{~s}$ shows two peaks at 530.5 and $532.7 \mathrm{eV}$ corresponding to the metaloxide and hydroxyl $(-\mathrm{OH})$ groups respectively in $\mathrm{Co}_{5} \mathrm{POM}$ and NCNTs (Figure 3c). The Co $2 \mathrm{p}$ spectra in Figure S8 (Supporting Information) shows doublet peaks originating from $\mathrm{Co}_{5} \mathrm{POM}$ consisting of $\mathrm{Co} 2 \mathrm{p}_{1 / 2}$ and Co2 $\mathrm{p}_{3 / 2}$ Co-oxygen bond. The W $4 \mathrm{f}$ spectra show doublet peak originating from $\mathrm{Co}_{5}$ POM consisting of $\mathrm{W} 4 \mathrm{f}_{7 / 2}$ and $4 \mathrm{f}_{5 / 2}$ at a binding energy of 35.4 and $37.5 \mathrm{eV}$, respectively (Figure 3d).

Electrochemical Studies. To probe the selectivity of the synthesized composite materials toward the electrochemical detection of DA, initially cyclic voltammetric $(\mathrm{CV})$ experiments were performed. Preliminary measurements were carried out using PVIM- $\mathrm{Co}_{5} \mathrm{POM}$ conjugate drop-coated on a graphite electrode and $\mathrm{CV}$ measurements were performed in $0.1 \mathrm{M}$ 
phosphate-buffered solution (PBS; pH 7.0) containing $500 \mu \mathrm{M}$ $\mathrm{AA}$ and $50 \mu \mathrm{M} \mathrm{DA}$ at a scan rate of $75 \mathrm{mV} \mathrm{s}^{-1}$. Figure $4 \mathrm{a}$ reveals the formation of redox peaks centered at 210 and 168 $\mathrm{mV}$ corresponding to oxidation of $\mathrm{DA}$ to dopaminoquinone and subsequent reduction to DA respectively. However, no peaks with respect to oxidation of AA was observed in $\mathrm{CV}$, and a feeble peak was observed for AA in differential pulse voltammetry (DPV) (Figure 4b) and the lower detection limit was found to be $10 \mu \mathrm{M}$ (Figure 5a). Despite the selective behavior, PVIM- $\mathrm{Co}_{5} \mathrm{POM}$ conjugate suffers from a broadened electrochemical response for DA oxidation attributed to the sluggish electron-transfer kinetics. Functionalized CNTs were incorporated to improve the electron-transfer process. Depending upon the nature of the functionalities present within the CNTs, it is possible to mediate and tune the sensitivity toward DA determination and electron transfer across the interface.

The PVIM- $\mathrm{Co}_{5} \mathrm{POM}$ conjugate was taken in combination with various NCNTs (NCNT-200, NCNT-400, and NCNT600 , detailed in the Supporting Information) designated as PVIM- $\mathrm{Co}_{5} \mathrm{POM} / \mathrm{NCNT}$ composite (synthesis detailed in Experimental Section) and performed the analysis under similar conditions. As expected, both PVIM- $\mathrm{Co}_{5} \mathrm{POM} /$ NCNT-400 and PVIM-Co 5 POM/NCNT-200 shows wellbehaved redox behavior however, the higher redox current was observed for PVIM- $\mathrm{Co}_{5} \mathrm{POM} / \mathrm{NCNT}-400$ composite, as shown in CV (Figure 4a). The differential activity towards electro-oxidation of DA could be because of the kinetics of the interfacial charge-transfer process, which in turn relates to the electron transfer at the electrode-electrolyte interface and was further studied by electrochemical impedance spectroscopy (EIS).

As evident from Figure 4c, the $R_{\mathrm{ct}}$ (charge-transfer resistance) is lower for PVIM- $\mathrm{Co}_{5} \mathrm{POM} / \mathrm{NCNT}-400$ composite compared to the other two catalysts. The higher $R_{\mathrm{ct}}$ at PVIM- $\mathrm{Co}_{5} \mathrm{POM}$ indicates dominance of sluggish kinetics because of the resistance at electrode-electrolyte interface. This fortifies the fact that the PVIM- $\mathrm{Co}_{5} \mathrm{POM} / \mathrm{NCNT}-400$ composite reveals faster kinetics towards electro-oxidation of DA because of the facilitated electron transport at the catalyst surface.

Further, the sensitivity of the PVIM- $-\mathrm{Co}_{5} \mathrm{POM} / \mathrm{NCNT}-400$ composite was carried out by varying the concentration of DA (500 pM to $600 \mu \mathrm{M})$ and keeping $\mathrm{AA}$ constant $(500 \mu \mathrm{M})$. Surprisingly, the PVIM- $\mathrm{Co}_{5} \mathrm{POM} / \mathrm{NCNT}-400$ depicted in Figure $5 \mathrm{c}$ shows a noticeable peak at a very low concentration of DA (500 pM) and a sharp intense peak at $1 \mathrm{nM}$. Subsequently, a sharp increase in the oxidation peak current was observed with increase in DA concentration (500 pM to $600 \mu \mathrm{M}$, Figure $5 \mathrm{~b}$ ) demonstrating the superior sensitivity towards the determination of DA. This was further supported by EIS studies (Figure 5d).

Interestingly, no oxidation peak corresponding to AA was observed even at this high AA concentration of $500 \mu \mathrm{M}$ indicating that PVIM- $-\mathrm{Co}_{5} \mathrm{POM} / \mathrm{NCNT}-400$ composite inhibits the diffusion of AA toward the electrode surface through plausible repulsive electrostatic interaction between anionic AA and a negatively charged cluster of $\mathrm{Co}_{5} \mathrm{POM}$ (Scheme 1$)$. It is important to note that no significant peak corresponding to the oxidation of AA was observed even with increase in concentration of DA ( $600 \mu \mathrm{M}$, Figure $5 \mathrm{~b})$, demonstrating the complete elimination of AA interference.

Similar experiments using PVIM- $\mathrm{Co}_{5} \mathrm{POM} / \mathrm{NCNT}-200$ (Figure S10, Supporting Information), PVIM-Co $\mathrm{C}_{5} \mathrm{POM} /$
NCNT-600 composite shows similar behavior but the peak current corresponding to oxidation of DA is lower in both of the cases compared to PVIM- $\mathrm{Co}_{5} \mathrm{POM} / \mathrm{NCNT}-400$ composite. It is noteworthy to mention that, the lowest detection limit was found to be 1 and $10 \mu \mathrm{M}$ respectively with the linear detection range of $1-300 \mu \mathrm{M}$ (Figure S11a) in both of the cases, which is lower than PVIM- $\mathrm{Co}_{5} \mathrm{POM} / \mathrm{NCNT}-400$ composite. This was further evidenced by EIS studies (Figure $\mathrm{S} 10 \mathrm{~b}$, Supporting Information) wherein $R_{\mathrm{ct}}$ decreases with increasing concentration of DA (up to $300 \mu \mathrm{M}$ ) and with further increase in DA concentration, $R_{\mathrm{ct}}$ increases (Figure $\mathrm{S} 10 \mathrm{C}$ ), and a shift in $R_{\mathrm{s}}$ (solution resistance) was observed (the oxidation peak current in DPV decreases, figure not shown) indicating the slow kinetics because of the less electron transfer at the electrode-electrolyte interface. Further control experiments using PVIM- $\mathrm{Co}_{5} \mathrm{POM} /$ oxidized CNT (OCNT)modified graphite electrode reveals a broadened electrochemical response toward oxidation of DA. Surprisingly, no peak corresponding to the oxidation of DA was observed up to $300 \mathrm{nM}$ concentration of DA, however, a pronounced broadened peak at $-30 \mathrm{mV}$ attributed to oxidation of $\mathrm{AA}$ was observed. Further increase in the concentration of DA, an additional peak appeared at $100 \mathrm{mV}$, and peak current increases with the subsequent increase in DA indicates the interference of AA (Figures 6 and S11, Supporting Information).

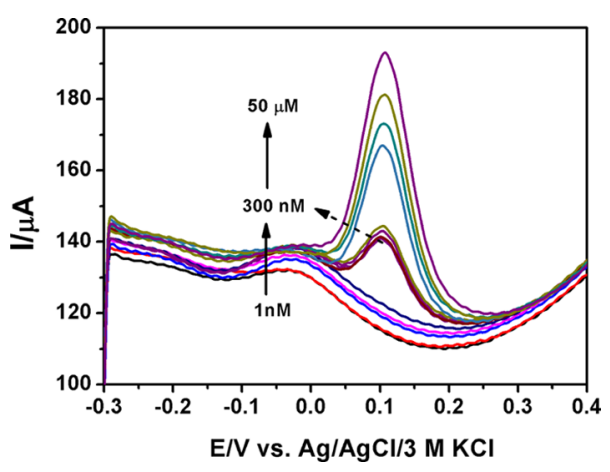

Figure 6. Differential pulse voltammograms of PVIM- $\mathrm{Co}_{5} \mathrm{POM} /$ OCNT in $0.1 \mathrm{M}$ PBS (pH 7.0) solution containing $500 \mu \mathrm{M}$ AA and various concentrations of DA at a step potential $10 \mathrm{mV}$, pulse amplitude $2 \mathrm{mV}$, pulse width $500 \mathrm{~ms}$, scan rate $10 \mathrm{mV} \mathrm{s}^{-1}$, CE: Pt wire, and $\mathrm{RE}: \mathrm{Ag} / \mathrm{AgCl} / 3 \mathrm{M} \mathrm{KCl}$.

The above results demonstrate the excellent sensitivity of PVIM-Co 5 POM/NCNT-400 composite toward the electrochemical detection of DA with a lowest limit of $500 \mathrm{pM}$ $(0.0005 \mu \mathrm{M})$ and selectivity with the linear detection range of $0.0005-600 \mu \mathrm{M}$ (Figure 5). This is one of the best catalyst reported so far towards the selective electrochemical detection of DA (comparison tabulated in Table 1). The selectivity of the proposed sensor was also assessed in the presence of UA nevertheless, neither significant peak corresponding to the oxidation of UA nor shift in the peak corresponding to the oxidation of DA was observed with a subsequent increase in the concentration of DA ( $200 \mu \mathrm{M}$, Figure S12), demonstrating the complete elimination of UA interference.

The plot of anodic and cathodic peak current with respect to square root of different scan rate reveals the linear response suggesting the electro-oxidation process of DA is the diffusioncontrolled reaction (Figures S13-S15, Supporting Information). In an attempt to explore this sensor for practical 
Table 1. Comparison of the Sensing Characteristics of the PVIM-Co ${ }_{5} \mathrm{POM} / \mathrm{NCNT}-400-\mathrm{Based}$ Sensor for the Determination of DA Over Different Electrodes

\begin{tabular}{|c|c|c|c|c|}
\hline electrode & ratio of AA: DA considered & linear range $(\mu \mathrm{M})$ & lowest detection limit $(\mu \mathrm{M})$ & Ref \\
\hline GA-RGO/AuNPs & $250 \mu \mathrm{M}: 5 \mu \mathrm{M}$ & $0.01-100.3$ & $0.0026^{b}$ & 24 \\
\hline $\mathrm{RGO} / \mathrm{TiO}_{2}$ & $1000 \mu \mathrm{M}: 2 \mu \mathrm{M}$ & $2-60$ & 6 & 25 \\
\hline $\mathrm{PA6} / \mathrm{PAH} / \mathrm{MWCNTs}^{a}$ & $100 \mu \mathrm{M}: 50 \mu \mathrm{M}$ & $1-70$ & $0.15^{b}$ & 26 \\
\hline $\mathrm{Ag}-\mathrm{Pt} / \mathrm{pCNFs}$ & $400 \mu \mathrm{M}: 100 \mu \mathrm{M}$ & $10-500$ & 0.11 & 9 \\
\hline $\operatorname{PNT}\left[\mathrm{Cu}(\text { aphyhist })_{4}\right]^{4+} /$ Nafion & $400 \mu \mathrm{M}: 40 \mu \mathrm{M}$ & $5-40$ & 2.80 & 10 \\
\hline EDTA-RG/Nafion & $10 \mathrm{mM}: 10 \mu \mathrm{M}$ & $0.2-25$ & 0.01 & 27 \\
\hline 3D $\mathrm{CNT}^{a}$-nanoweb & $1000 \mu \mathrm{M}: 20 \mu \mathrm{M}$ & $1-20$ & & 28 \\
\hline graphene & $1000 \mu \mathrm{M}: 4 \mu \mathrm{M}$ & $4-100$ & 2.64 & 29 \\
\hline$\left\{\mathrm{PEI} /\left[\left(\mathrm{P}_{2} \mathrm{~W}_{17} \mathrm{~V}-\mathrm{CuO}\right) /(\mathrm{CS}-\mathrm{Pd})\right]_{7} /\left(\mathrm{P}_{2} \mathrm{~W}_{17} \mathrm{~V}-\mathrm{CuO}\right)\right\} / \mathrm{ITO}$ & $1000 \mu \mathrm{M}: 10 \mu \mathrm{M}$ & $0.25-217$ & $0.045^{b}$ & 21 \\
\hline$(\mathrm{POMOF}) / \mathrm{rGO}$ & $200 \mu \mathrm{M}: 50 \mu \mathrm{M}$ & $1-200$ & $0.080^{b}$ & 20 \\
\hline PMo11V@GFs & $10 \mu \mathrm{M}: 2 \mu \mathrm{M}$ & $2-300$ & 0.88 & 30 \\
\hline $\mathrm{PVIM}-\mathrm{Co}_{5} \mathrm{POM} / \mathrm{NCNT}-400$ & $500 \mu \mathrm{M}: 500 \mathrm{pM}$ & $500 \mathrm{pM}$ to $600 \mu \mathrm{M}$ & $0.0005(500 \mathrm{pM})$ & this work \\
\hline
\end{tabular}

applications, the PVIM- $\mathrm{Co}_{5} \mathrm{POM} / \mathrm{NCNT}-400$ composite was analyzed for the detection of DA in real sample using commercially available DA hydrochloride injections $(40 \mathrm{mg}$ $\mathrm{mL}^{-1}$ ) by standard addition method, and the recovery of the sample was in the range of $95-102 \%$, demonstrating the applicability of the PVIM- $\mathrm{Co}_{5} \mathrm{POM} / \mathrm{NCNT}-400$ composite for real-time analysis as well. Further, the stability of the PVIM- $\mathrm{Co}_{5} \mathrm{POM} / \mathrm{NCNT}-400$ composite was evaluated by cyclic voltammetry in a solution containing $50 \mu \mathrm{M}$ DA (Figure S16, Supporting Information), which evidently demonstrates the negligible decay in either current or potential even after 100 consecutive cycles.

The enhanced selective electrochemical response obtained can be attributed to the specific electrostatic interaction between the negatively charged $\mathrm{Co}_{5} \mathrm{POM}$ and DA (positively charged) through effective stabilization at NCNTs surface. Moreover, the synergistic effect arising from the strong $\pi-\pi$ interaction between NCNTs and imidazolium cations of PVIM, along with the electrostatic interaction between PVIM and $\mathrm{Co}_{5} \mathrm{POM}$, which further enhances the electrochemical response through accelerating the electron transfer from $\mathrm{Co}_{5} \mathrm{POM}$ to the electrode surface. $^{18}$

\section{CONCLUSIONS}

Here, we demonstrated a novel sandwich POM $\left[\mathrm{WCo}_{3}\left(\mathrm{H}_{2} \mathrm{O}\right)_{2}\left(\mathrm{CoW}_{9} \mathrm{O}_{34}\right)_{2}\right]^{12-}$ and poly(ionic liquid) $\left[\mathrm{PVIM}^{+}\right]$in combination with NCNTs as an electrochemical sensor for a highly selective and ultrasensitive detection of DA. The novel PVIM-Co ${ }_{5} \mathrm{POM} / \mathrm{NCNT}-400$ composite demonstrates a superior selectivity and sensitivity evident from the DPV studies with a lowest detection limit of 500 pM $(500 \times$ $\left.10^{-12} \mathrm{M}\right)$. The linear detection range was found to be $500 \mathrm{pM}$ to $600 \mu \mathrm{M}$, even in presence of higher concentration of $\mathrm{AA}$ $(500 \mu \mathrm{M})$, demonstrating the complete elimination of AA and $\mathrm{UA}$ interference. The ionic polymer acts as a bridge between $\mathrm{Co}_{5} \mathrm{POM}$ and NCNTs, which provides physical and chemical stability simultaneously to eliminate the interference of AA with increased sensitivity. Employing the efficient heterogenization of $\mathrm{Co}_{5} \mathrm{POM}$ catalyst by PVIM over NCNTs provides the synergy between PVIM-POM catalyst and NCNTs, which enhances the electron transport at the electrode/electrolyte interface and eliminates the interference of $\mathrm{AA}$ and $\mathrm{UA}$ at physiological $\mathrm{pH}$ (7.4).

\section{EXPERIMENTAL SECTION}

Materials. All of the reagents and solvents used in the synthesis of $\mathrm{Na}_{12}\left[\mathrm{Co}_{5} \mathrm{POM}\right]$ and PVIMBr were purchased from Alfa Aesar; $\mathrm{KCl}, \mathrm{KH}_{2} \mathrm{PO}_{4}, \mathrm{~K}_{2} \mathrm{HPO}_{4}$, and isopropyl alcohol were from Merck. Dopamine hydrochloride (>99\% crystalline) and ascorbic acid ( $99 \%$ crystalline) were from Sigma-Aldrich and dopamine hydrochloride injections $\left(40 \mathrm{mg} \mathrm{mL} \mathrm{m}^{-1}\right.$ ) were purchased from Neon Laboratories Ltd. Carbon nanotubes were purchased from Applied Science, USA. The aqueous solutions were prepared using deionized water obtained from a Millipore system $\left(>12 \mathrm{M} \Omega \mathrm{cm}^{-1}\right)$. PBS $(0.1 \mathrm{M})$ was prepared from the stock solutions of $0.1 \mathrm{M} \mathrm{KH}_{2} \mathrm{PO}_{4}$ and $0.1 \mathrm{M} \mathrm{K}_{2} \mathrm{HPO}_{4}$.

Synthesis. Poly(1-vinylbutylimidazolium bromide) (PVIMBr). Synthesis of poly(1-vinylbutylimidazolium bromide) (PVIMBr) was performed as follows, according to our previously reported procedure. $^{18}$

Poly(1-vinylimidazole) (1). A Schlenk tube was charged with 1 -vinylimidazole $(0.941 \mathrm{~g}, 10.00 \mathrm{mmol})$, azobis(isobutyronitrile) (1.0 wt \%, $0.013 \mathrm{~g}$ ), and $4.0 \mathrm{~mL}$ of dry toluene. The mixture was degassed under vacuum using three freeze-thaw cycles, and the presence of oxygen, if any, was removed by argon purging for $30 \mathrm{~min}$. The reaction mixture was heated at $70{ }^{\circ} \mathrm{C}$ for $24 \mathrm{~h}$. The obtained solid was purified using diethyl ether and dried under vacuum to yield $\mathbf{1}$ as a white powder $(0.750 \mathrm{~g}, 80 \%)$. The synthesized polymer is soluble in water and methanol but insoluble in chloroform, tetrahydrofuran, and toluene. ${ }^{1} \mathrm{H} \mathrm{NMR}\left(\mathrm{D}_{2} \mathrm{O}, \delta \mathrm{ppm}\right)$ (Figure S1, Supporting Information): $7.06-6.64$ (broad, $3 \mathrm{H}$, imidazole ring proton), 3.74-2.57 (broad, $1 \mathrm{H}), 2.12-1.9$ (broad, $2 \mathrm{H}$ ).

Poly(1-vinylbutyl imidazolium bromide) [PVIMBr] (2). A Schlenk tube fitted with a condenser was charged with poly(1vinylimidazole) 1 ( $0.339 \mathrm{~g}, 3.62 \mathrm{mmol}), n$-butyl bromide $(0.543$ $\mathrm{g}, 3.98 \mathrm{mmol})$, and dry methanol. The reaction mixture was heated at $60{ }^{\circ} \mathrm{C}$ for $48 \mathrm{~h}$ and further added to acetone to obtain a precipitate of $2(0.772 \mathrm{~g}, 92.3 \%) .{ }^{1} \mathrm{H}$ NMR (DMSO-d $\mathrm{d}_{6} \delta$ $\mathrm{ppm}$ ) (Figure S2, Supporting Information): 9.61 (broad, $1 \mathrm{H}$, $\mathrm{NCHN}$ ), 7.83-7.73 (broad, 2H, NCHCHN), 4.12-3.84 (broad, 4H), 2.51-2.49 (broad, 2H), 1.84 (broad, 2H), 1.33 (broad, $2 \mathrm{H}$ ), 0.94 (broad, $2 \mathrm{H}$ ).

$\mathrm{Na}_{12}\left[\mathrm{WCO}_{3}\left(\mathrm{H}_{2} \mathrm{O}\right)_{2}\left(\mathrm{CoW}_{9} \mathrm{O}_{34}\right)_{2}\right]$. The $\mathrm{Na}_{12}\left[\mathrm{WCo}_{3}\left(\mathrm{H}_{2} \mathrm{O}\right)_{2}-\right.$ $\left.\left(\mathrm{CoW}_{9} \mathrm{O}_{34}\right)_{2}\right]$ denoted as $\mathrm{Na}_{12}\left[\mathrm{Co}_{5} \mathrm{POM}\right]$ was synthesized under microwave heating for the first time ${ }^{22}$ (detailed experimental parameters are given in Table S2, Supporting Information). A mixture of $\mathrm{Na}_{2} \mathrm{WO}_{4} \cdot 2 \mathrm{H}_{2} \mathrm{O}(16.000 \mathrm{~g}, 48.48$ $\mathrm{mmol}$ ), $60 \mathrm{~mL}$ of $\mathrm{H}_{2} \mathrm{O}$, and $2 \mathrm{~mL}$ of conc. $\mathrm{HNO}_{3}$ was taken in a 
microwave reaction vessel and microwave irradiated for $30 \mathrm{~min}$ at $80-85{ }^{\circ} \mathrm{C}$. After cooling, solid $\mathrm{Co}\left(\mathrm{NO}_{3}\right)_{2} \cdot 6 \mathrm{H}_{2} \mathrm{O}(3.656 \mathrm{~g}$, $12.56 \mathrm{mmol}$ ) was added and further microwave irradiated for $30 \mathrm{~min}$ at $85-90{ }^{\circ} \mathrm{C}$. The obtained hot solution was filtered, and the filtrate was subjected to crystallization. After 2-3 days, deep-green-colored needle-shaped crystals were collected by filtration. The obtained crystals were recrystallized from water, collected by filtration, and dried at $\sim 80{ }^{\circ} \mathrm{C}$ under high vacuum to obtain $\mathrm{Na}_{12}\left[\mathrm{WCo}_{3}\left(\mathrm{H}_{2} \mathrm{O}\right)_{2}\left(\mathrm{CoW}_{9} \mathrm{O}_{34}\right)_{2}\right]$ and designated as ( $\left.\mathrm{Co}_{5} \mathrm{POM}\right)$. (Yield: $\left.1.562 \mathrm{~g}, 0.30 \mathrm{mmol}, 48.38 \%\right)$. FT-IR $\left(\mathrm{cm}^{-1}\right): 1622,1388,916,858,684,531$.

PVIM- $\mathrm{CO}_{5} \mathrm{POM}$ Conjugate. [PVIM $]\left[\mathrm{Co}_{5} \mathrm{POM}\right]$ conjugate was prepared by ion-exchange method. In a Schlenk tube, $\mathrm{Na}_{12}\left[\mathrm{Co}_{5} \mathrm{POM}\right]$ was taken and dissolved in $10 \mathrm{~mL}$ of water to get a clear greenish solution. A solution of PVIMBr (dissolved in $15 \mathrm{~mL}$ water) was added slowly to the resulting solution. Immediately, the clear solution becomes coagulated, and it was then heated to $80{ }^{\circ} \mathrm{C}$ for $2 \mathrm{~h}$. The resultant emulsion suspension was cooled to room temperature and filtered through frit (the clear colorless filtrate indicates the formation of the desired conjugate). After that, it was washed with water and dried at $\sim 70{ }^{\circ} \mathrm{C}$ under high vacuum to get greenish colored $[\mathrm{PVIM}]\left[\mathrm{Co}_{5} \mathrm{POM}\right]$ conjugate (yield $0.328 \mathrm{~g}, 0.05 \mathrm{mmol}$, $83.3 \%)$.

Synthesis of NCNTs. CNTs with inner diameters of 20-50 $\mathrm{nm}$ and outer diameters of 70-200 nm were obtained from Applied Sciences Inc. (Ohio, USA). Nitrogen functional groups were introduced to OCNTs (synthesis detailed in Supporting Information) by heating under ammonia with a total flow rate of $25 \mathrm{sccm}$ at 200,400 , and $600{ }^{\circ} \mathrm{C}$ for $6 \mathrm{~h}$ and are designated as NCNT-200, NCNT-400, and NCNT-600, respectively, (details given in the Supporting Information). ${ }^{23}$

Physical Characterization. SC-XRD Studies. The crystal structure of the synthesized $\mathrm{Co}_{5} \mathrm{POM}$ was probed using single graphite-monochromated Mo K $\alpha$ radiation $(\lambda=0.71073 \AA)$ on a Bruker D8 SMART APEX2 CMOS diffractometer at $293 \mathrm{~K}$. Data integration was performed using SAINT. SIR97 was used to solve the structure, and the refinement was performed using SHELXL 2013. The obtained structure was corrected using routine Lorentz and polarization corrections, and empirical absorption corrections were performed using SADABS. The crystal data and refinement parameters are compiled and are given in Table S3 (Supporting Information). CIF file for the $\mathrm{Na}_{12}\left[\mathrm{Co}_{5} \mathrm{POM}\right]$ is deposited with the Cambridge Crystallographic Data Centre (CCDC no. 1558372).

Morphology and Elemental Analysis. The morphology of the $\mathrm{Na}_{12}\left[\mathrm{Co}_{5} \mathrm{POM}\right], \mathrm{PVIM}-\mathrm{Co}_{5} \mathrm{POM}$, and PVIM-Co 5 POM/ NCNT composites was analyzed using field-emission scanning electron microscope (ZEISS, Sigma VP FE-SEM). FT-IR spectra (2\% sample in $\mathrm{KBr}$ ) were recorded using a Bruker TENSOR-II spectrometer in the range of $600-4000 \mathrm{~cm}^{-1}$ with a spectral resolution of $4 \mathrm{~cm}^{-1}$ and 100 scans. FT-IR data were collected and analyzed by OPUS. UV-vis measurements were performed using Shimadzu UV-2600 spectrophotometer.

XPS of the catalyst materials were recorded (PHI VersaProbe II Spectrometer) in an ultrahigh vacuum chamber at $10^{-9}$ Torr using $\mathrm{Al} \mathrm{K} \alpha$ radiation $(h \nu=1486.6 \mathrm{eV})$. The measurements were performed at a pass energy of $200 \mathrm{eV}$. The spectra were calibrated with respect to $\mathrm{C}$ (1s) peak at $284.5 \mathrm{eV}$ with a precision of $\pm 0.2 \mathrm{eV}$.

Electrochemical Studies. All of the electrochemical experiments were performed in a single-compartment electrochemical cell with three electrode assembly consisting of a graphite electrode $(\varnothing 3 \mathrm{~mm})$ as the working electrode hosting the catalyst, $\mathrm{Pt}$ wire as the $\mathrm{CE}$, and $\mathrm{Ag} / \mathrm{AgCl} / 3 \mathrm{M} \mathrm{KCl}$ as the $\mathrm{RE}$. Prior to each experiment, graphite electrodes were polished using different grits of emery paper and washed thoroughly using deionized water, which was further ultrasonicated in deionized water for $5 \mathrm{~min}$ to remove any physisorbed particles. The PVIM- $\mathrm{Co}_{5} \mathrm{POM} / \mathrm{NCNT}$ composite slurry was prepared by homogeneously grinding the mixture of PVIM- $-\mathrm{Co}_{5} \mathrm{POM}$ and NCNTs (synthesis detailed in the Supporting Information) (1.25 mg, 70:30 wt \%) using pestle and mortar for $1 \mathrm{~h}$, and the obtained product was dispersed in a mixture of isopropyl alcohol (IPA, $20 \mu \mathrm{L})$ and deionized water $(480 \mu \mathrm{L}, 12 \mathrm{M} \Omega)$ and further sonicated for $30-40 \mathrm{~min}$. The $20 \mu \mathrm{L}(50 \mu \mathrm{g})$ of the obtained slurry was drop-coated over polished graphite electrode and dried at room temperature. The electrochemical measurements were performed using Bio-Logic (VSP 300), and DPV measurements were carried out at pulse amplitude of 2 $\mathrm{mV}$, pulse width of $500 \mathrm{~ms}$, and step potential of $10 \mathrm{mV}$ at a scan rate of $10 \mathrm{mV} \mathrm{s}^{-1}$. The EIS measurements were performed at a DC voltage of $150 \mathrm{mV}$ over a frequency range between 10 $\mathrm{MHz}$ and $10 \mu \mathrm{Hz}$. All measurements were repeated at least 5 times.

\section{ASSOCIATED CONTENT}

\section{S Supporting Information}

The Supporting Information is available free of charge on the ACS Publications website at DOI: 10.1021/acsomega.7b02049.

Synthesis of NCNTs and OCNTs, physical characterization of $\mathrm{Na}_{12}\left(\mathrm{Co}_{5} \mathrm{POM}\right), \mathrm{PVIM}-\mathrm{Co}_{5} \mathrm{POM}$, and PVIM- $\mathrm{Co}_{5} \mathrm{POM} / \mathrm{NCNT}$ composites (NMR, UV, FTIR, DFT, SEM, XPS, and SC-XRD), and detailed electrochemical studies of the composite (PDF) Crystallographic data of $\mathrm{Na}_{12}\left[\mathrm{WCo}_{3}\left(\mathrm{H}_{2} \mathrm{O}\right)_{2}-\right.$ $\left.\left(\mathrm{CoW}_{9} \mathrm{O}_{34}\right)_{2}\right](\mathrm{CIF})$

\section{AUTHOR INFORMATION}

\section{Corresponding Authors}

*E-mail: dmandal@iitrpr.ac.in (D.M.).

*E-mail: tharamani@iitrpr.ac.in (T.C.N.).

ORCID *

Debaprasad Mandal: 0000-0003-4701-543X

Tharamani C. Nagaiah: 0000-0003-3545-6668

Notes

The authors declare no competing financial interest.

\section{ACKNOWLEDGMENTS}

T.C.N. thanks the Nanomission, Department of Science and Technology (DST) (SR/NM/NS-1376/2014). D.M. thanks the Department of Atomic Energy (DAE), India, (2013/37C/ 57/BRNS) and DST India (SB/FT/CS-046/2012); N.T., S.D.A., M.K., and A.K.P. thanks IIT Ropar for the fellowship.

\section{REFERENCES}

(1) Basu, S.; Dasgupta, P. S. Dopamine, a neurotransmitter, influences the immune system. J. Neuroimmunol. 2000, 102, 113-124.

(2) Schultz, W. Multiple Dopamine Functions at Different Time Courses. Annu. Rev. Neurosci. 2007, 30, 259-288.

(3) Gaskill, P. J.; Yano, H. H.; Kalpana, G. V.; Javitch, J. A.; Berman, J. W. Dopamine Receptor Activation Increases HIV Entry into Primary Human Macrophages. PLoS One 2014, 9, No. e108232.

(4) Prasad, B. B.; Jauhari, D.; Tiwari, M. P. A dual-template imprinted polymer-modified carbon ceramic electrode for ultra trace simulta- 
neous analysis of ascorbic acid and dopamine. Biosens. Bioelectron. 2013, 50, 19-27.

(5) Kondo, T.; Niwano, Y.; Tamura, A.; Imai, J.; Honda, K.; Einaga, Y.; Tryk, D. A.; Fujishima, A.; Kawai, T. Enhanced electrochemical response in oxidative differential pulse voltammetry of dopamine in the presence of ascorbic acid at carboxyl-terminated boron-doped diamond electrodes. Electrochim. Acta 2009, 54, 2312-2319.

(6) Euczak, T. Gold and Nanogold Electrodes Modified with Gold Nanoparticles and meso-2,3-Dimercaptosuccinic Acid for the Simultaneous, Sensitive and Selective Determination of Dopamine and Its Biogenic Interferents. Electroanalysis 2014, 26, 2152-2160.

(7) Euczak, T.; Bełtowska-Brzezinska, M. Gold electrodes modified with gold nanoparticles and thio compounds for electrochemical sensing of dopamine alone and in presence of potential interferents. A comparative study. Microchim. Acta 2011, 174, 19-30.

(8) Wang, C.; Du, J.; Wang, H.; Zou, C.; Jiang, F.; Yang, P.; Du, Y. A facile electrochemical sensor based on reduced graphene oxide and $\mathrm{Au}$ nanoplates modified glassy carbon electrode for simultaneous detection of ascorbic acid, dopamine and uric acid. Sens. Actuators, $B$ 2014, 204, 302-309.

(9) Huang, Y.; Miao, Y.-E.; Ji, S.; Tjiu, W. W.; Liu, T. Electrospun carbon nanofibers decorated with $\mathrm{Ag}-\mathrm{Pt}$ bimetallic nanoparticles for selective detection of dopamine. ACS Appl. Mater. Interfaces 2014, 6, 12449-12456.

(10) de Oliveira Matos, I.; Alves, W. A. Electrochemical Determination of Dopamine Based on Self-Assembled Peptide Nanostructure. ACS Appl. Mater. Interfaces 2011, 3, 4437-4443.

(11) Li, J.; Zhao, J.; Wei, X. A sensitive and selective sensor for dopamine determination based on a molecularly imprinted electropolymer of o-aminophenol. Sens. Actuators, B 2009, 140, 663-669.

(12) Joshi, A.; Chavan, S. N.; Mandal, D.; Nagaiah, T. C. Ionic Liquid and Nitrogen Doped Carbon Nanotubes Composite Material for Sensitive and Selective Detection of Dopamine. Electroanalysis 2016, 28, 2373-2381.

(13) Wang, Y.; Weinstock, I. A. Polyoxometalate-decorated nanoparticles. Chem. Soc. Rev. 2012, 41, 7479-7496.

(14) Wang, X.-S.; Huang, Y.-B.; Lin, Z.-J.; Cao, R. Phosphotungstic acid encapsulated in the mesocages of amine-functionalized metalorganic frameworks for catalytic oxidative desulfurization. Dalton Trans. 2014, 43, 11950-11958.

(15) Liu, D.; Lu, Y.; Tan, H.-Q.; Chen, W.-L.; Zhang, Z.-M.; Li, Y.G.; Wang, E.-B. Polyoxometalate-based purely inorganic porous frameworks with selective adsorption and oxidative catalysis functionalities. Chem. Commun. 2013, 49, 3673-3675.

(16) Yin, Q.; Tan, J. M.; Besson, C.; Geletii, Y. V.; Musaev, D. G.; Kuznetsov, A. E.; Luo, Z.; Hardcastle, K. I.; Hill, C. L. A Fast Soluble Carbon-Free Molecular Water Oxidation Catalyst Based on Abundant Metals. Science 2010, 328, 342-345.

(17) Herrmann, S.; Aydemir, N.; Nägele, F.; Fantauzzi, D.; Jacob, T.; Travas-Sejdic, J.; Streb, C. Enhanced Capacitive Energy Storage in Polyoxometalate-Doped Polypyrrole. Adv. Funct. Mater. 2017, 27, 1700881 .

(18) Singh, V.; Adhikary, S. D.; Tiwari, A.; Mandal, D.; Nagaiah, T. C. Sustainable Non-Noble Metal Bifunctional Catalyst for OxygenDepolarized Cathode and $\mathrm{Cl} 2$ Evolution in $\mathrm{HCl}$ Electrolysis. Chem. Mater. 2017, 29, 4253-4264.

(19) Rhule, J. T.; Hill, C. L.; Judd, D. A.; Schinazi, R. F. Polyoxometalates in Medicine. Chem. Rev. 1998, 98, 327-358.

(20) Zhang, W.; Jia, G.; Li, Z.; Yuan, C.; Bai, Y.; Fu, D. Selective Electrochemical Detection of Dopamine on Polyoxometalate-Based Metal-Organic Framework and Its Composite with Reduced Graphene Oxide. Adv. Mater. Interfaces 2017, 4, 1601241.

(21) Zhang, L.; Ning, L.; Li, S.; Pang, H.; Zhang, Z.; Ma, H.; Yan, H. Selective electrochemical detection of dopamine in the presence of uric acid and ascorbic acid based on a composite film modified electrode. RSC Adv. 2016, 6, 66468-66476.

(22) Tourné, C. M.; Tourné, G. F.; Zonnevijlle, F. Chiral polytungstometalates $\left[\mathrm{WM}_{3}\left(\mathrm{H}_{2} \mathrm{O}\right)_{2}\left(\mathrm{XW}_{9} \mathrm{O}_{34}\right)_{2}\right]^{12-}(\mathrm{X}=\mathrm{M}=\mathrm{Zn}$ or $\mathrm{Co})$ and their M-substituted derivatives. Syntheses, chemical, structural and spectroscopic study of some D, L sodium and potassium salts. J. Chem. Soc., Dalton Trans. 1991, 143-155.

(23) Nagaiah, T. C.; Kundu, S.; Bron, M.; Muhler, M.; Schuhmann, W. Nitrogen-doped carbon nanotubes as a cathode catalyst for the oxygen reduction reaction in alkaline medium. Electrochem. Commun. 2010, 12, 338-341.

(24) Thirumalraj, B.; Rajkumar, C.; Chen, S.-M.; Palanisamy, S. OnePot Green Synthesis of Graphene Nanosheets Encapsulated Gold Nanoparticles for Sensitive and Selective Detection of Dopamine. Sci. Rep. 2017, 7, 41213.

(25) How, G. T. S.; Pandikumar, A.; Ming, H. N.; Ngee, L. H. Highly exposed $\{001\}$ facets of titanium dioxide modified with reduced graphene oxide for dopamine sensing. Sci. Rep. 2014, 4, 5044.

(26) Mercante, L. A.; Pavinatto, A.; Iwaki, L. E. O.; Scagion, V. P.; Zucolotto, V.; Oliveira, O. N., Jr.; Mattoso, L. H. C.; Correa, D. S. Electrospun polyamide 6/poly (allylamine hydrochloride) nanofibers functionalized with carbon nanotubes for electrochemical detection of dopamine. ACS Appl. Mater. Interfaces 2015, 7, 4784-4790.

(27) Hou, S.; Kasner, M. L.; Su, S.; Patel, K.; Cuellari, R. Highly sensitive and selective dopamine biosensor fabricated with silanized graphene. J. Phys. Chem. C 2010, 114, 14915-14921.

(28) Zhao, J.; Zhang, W.; Sherrell, P.; Razal, J. M.; Huang, X.-F.; Minett, A. I.; Chen, J. Carbon nanotube nanoweb-bioelectrode for highly selective dopamine sensing. ACS Appl. Mater. Interfaces 2011, 4, 44-48.

(29) Kim, Y.-R.; Bong, S.; Kang, Y.-J.; Yang, Y.; Mahajan, R. K.; Kim, J. S.; Kim, H. Electrochemical detection of dopamine in the presence of ascorbic acid using graphene modified electrodes. Biosens. Bioelectron. 2010, 25, 2366-2369.

(30) Fernandes, D. M.; Freire, C. Carbon NanomaterialPhosphomolybdate Composites for Oxidative Electrocatalysis. ChemElectroChem 2015, 2, 269-279. 